\title{
COMBINED USE OF SPACE-BORNE OBSERVATIONS OF NO2 AND REGIONAL CTM MODEL FOR AIR QUALITY MONITORING IN NORTHERN ITALY
}

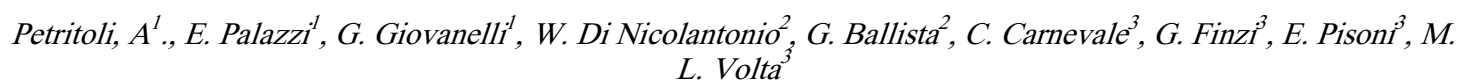

${ }^{1}$ Institute of Atmospheric Science and Climate, ISAC-CNR, via P. Gobetti 101, 40129, Bologna, Italy

${ }^{2}$ Carlo Gavazzi Space at ISAC-CNR, via P. Gobetti 101, 40129, Bologna, Italy

${ }^{3}$ Department of Electronics for Automation, University of Brescia, Italy

\begin{abstract}
The use of space-borne measurements of trace gas constituents for air quality monitoring is considerably increased during the past decade. This is due mainly to the new generation sensors able to observe large areas with good temporal resolution and due to new assimilation techniques that allow a synergetic use of information from satellite and from Chemical Transport Models (CTM). In fact the in situ sampling method used by the local environmental agencies for air quality monitoring is becoming too expensive to be further continued without a sensible reduction in the number of observing stations.

In this paper we present the work that has been performed so far within the QUITSAT project funded by the Italian Space Agency. SCIAMACHY (Uv-Vis spectrometer on board ESA-ENVISAT platform from 2002) observations of earth radiance are used to retrieve NO2 tropospheric column by DOAS spectrometric technique and radiative transfer modelling for AMF computation. Such kind of product has been widely used to estimate emissions, to monitor pollution hot spot as well as cross country and intercontinental transport. Within this work we have merged the column measurements of nitrogen dioxide with the simulations of the Transport Chemical Aerosol Model (TCAM) to improve the model output at the ground level. The method used is a weighted rescaling of the model column in the troposphere according to the SCIAMACHY observations where the weights are the measurement errors and the model column variances within the satellite ground-pixel, respectively. The employed data are related to the Northern Italy area.

The obtained ground concentrations of $\mathrm{NO} 2$ have been compared with in-situ observations performed by the regional environmental agencies. Results show good agreement mainly where well horizontal mixing is present. The ground concentration from SCIAMACHY-TCAM gives an average NO2 amount within the satellite ground-pixel of $30 \times 60 \mathrm{~km}^{2}$ that is important information for air quality assessment on a regional and/or national scale not easy to obtain only with ground-based observations. Our conclusions thus stress also the actual potential role of satellite observations combined with regional CTM models in the context of air quality monitoring, mainly in rural area, where the ground-based observations are missing.
\end{abstract}

Key words: Earth Observation Satellite data, Chemical Transport Models, $\mathrm{NO}_{2}$.

\section{INTRODUCTION}

Satellite borne observations of tropospheric trace gases composition has been widely used for different kind of atmospheric research issues: from climatic considerations (Richter et al., 2005; van der A et al., 2008) to air pollution monitoring (Wenig et al., 2003). Their main positive characteristics are global coverage and fair spatial resolution but still remain strong limitation in time resolution and requirements for the atmospheric conditions during measurement (mainly for the small cloud coverage and low aerosol loading).

As a matter of fact from the work of Richter and Burrows (2002), which firstly gave a look at tropospheric pollution problem from a global point of view, satellite observations of trace constituents seem to deserve a consistent role in the study and monitoring of air pollution.

But one of the main problem that satellite observations have to face in order to be used in air quality assessment is the unknown of pollutants vertical distribution. In fact, the only information we can obtain from space-borne instruments concerning the troposphere is column abundance, i.e. the concentration of the trace constituent integrated along the vertical direction. Such measurements can not always distinguish between pollution transported from other places and then located presumably in the free troposphere and pollution at lower level that can be in direct contact with population.

So if the spatial resolution as well as the time resolution have been improved from GOME (Burrows et al., 1999) on ERS-2 to OMI (Veefkind et al., 2006) on AURA through SCIAMACHY (Bovensmann et al., 1999) on ENVISAT, the information on the vertical resolved profile of concentration in the lower troposphere can not be easily solved with new approach to measurement geometry and/or inversion techniques. For this reason the integration with other tools is required. Assimilation of satellite observations into Chemical and Trasport Models (CTM) is a possible solution that has been already used mainly for stratospheric measurements (Lahoz et al, 2007) and with different purposes not connected to air pollution monitoring. Ground based measurements have been used so far for this scope instead (Elbern et al, 2001) but one of the advantages of satellite data is that its spatial resolution is similar to that of a CTM working on a regional scale, and its coverage is usually homogeneous over the considered domain.

What we propose in this paper are the results of a research work performed within a national project called QUITSAT, funded by the Italian Space Agency (ASI), and focused on the combined use of satellite data and CTM simulations to improve the monitoring of trace gases concentration at ground level. Our work is based on the observations of nitrogen dioxide $\left(\mathrm{NO}_{2}\right)$ provided by the SCIAMACHY sensor on board ESA ENVISAT platform and 
model simulations obtained from TCAM model (Carnevale et. al, 2008). In the subsequent sessions we present briefly the developed methodology, the results obtained in terms of $\mathrm{NO}_{2}$ concentrations at ground levels and the validation of the method by means of comparison with ground-based measurements performed by the regional environmental agencies.

\section{METHODOLOGY}

One of the aims of the QUITSAT project is to provide a prototype system to monitor air pollution also in terms of ground concentrations of main trace gases pollutants such as nitrogen dioxide that is to have a near real time analysis of what happened the day before in the considered domain. We used for this scope SCIAMACHY data and TCAM simulations both described in the following subsections as well as the merging method we have developed.

\section{Satellite data}

The primary objective of the SCanning Imaging Absorption SpectroMeter for Atmospheric CHartographY (SCIAMACHY) mission is to perform global measurements of trace gases in the troposphere and in the stratosphere (Bovensmann et al., 1999). The solar radiation transmitted, backscattered and reflected from the atmosphere is recorded at relatively high resolution $(0.2 \mathrm{~nm}$ to $0.5 \mathrm{~nm})$ over the range $240 \mathrm{~nm}$ to $1700 \mathrm{~nm}$, and in selected regions between $2000 \mathrm{~nm}$ and $2400 \mathrm{~nm}$ with different viewing geometries: nadir, limb, and sun/moon occultation. In this work we used only nadir observations in the UV-Vis spectral region to obtain the nitrogen dioxide slant column using the DOAS (Differential Optical Absorption Spectroscopy) technique (Platt, 1999). The stratospheric contribution to the total column is removed according to the method proposed by Richter and Burrows (2002) and the obtained tropospheric slant column is converted into tropospheric vertical column using the Air Mass Factor calculated with the PROMSAR model (Palazzi et al., 2005). The satellite ground pixel extension can be different depending on the measurements mode: in the $400 \mathrm{~nm}$ spectral region at mid-latitudes its dimension is about $30 \times 60 \mathrm{~km}^{2}$ and the overpass time is at 10:30 am Local Time. As briefly mentioned above one of the most important limitation of this kind of remote sensing measurements in the UV-Visible part of the solar spectrum is the influence of clouds in the instrumental field of view. In this case the interpretation of the observed signal is too complicated and usually ground pixel with cloud cover greater than few percent are removed from the analysis.

\section{Chemical Transport Model simulations}

GAMES modelling system (Volta et al., 2006) has been used in this study. The system harmonizes three main modules: (a) the multi-phase Eulerian 3D photochemical model TCAM (Transport Chemical Aerosol Model, (Carnevale et al., 2008); (b) the meteorological pre-processor PROMETEO; (c) the emission processor POEMPM (Carnevale et al., 2008) specifically designed to produce present and alternative emission scenarios. In this study GAMES has been applied over an area covering the entire Po Valley. The domain $(640 \mathrm{~km} \times 480 \mathrm{~km})$ has been horizontally subdivided into $64 \times 48$ cells, with a resolution of $10 \mathrm{~km} \times 10 \mathrm{~km}$ each. Vertical domain extends up to 3900 $\mathrm{m}$ a.g.l., and is subdivided into 11 layers of growing thickness. Simulations have been performed getting initial and boundary conditions by a nesting procedure from the results of CHIMERE simulations over Europe. The point sources and area emissions have been chemically and temporally adjusted to TCAM requirements and have been derived by CTN-ACE Italian modelling intercomparison project. Meteorological fields have been created with MM5 model and adapted to TCAM through PROMETEO pre-processor. With these features, the base case simulation (year 2004) has been simulated and validated in the frame of QUITSAT project. In this work TCAM NO2 ground concentrations have been extracted, at satellite passing hours, to be merged with SCIAMACHY measurements.

\section{Merging the two data}

The approach we have followed to merge satellite data with model simulation was aimed by a time saving goal and by the fact that satellite data (SCIAMACHY in particular) have still a low temporal resolution to be assimilated in a regional model. The only advantage we can have is in terms of ground concentration at the satellite overpass. At this time we can merge space-borne column measurements and CTM 3D runs to improve the accuracy of the trace gas ground concentrations simulated by the model. This is done according to the following steps:

i) The $\mathrm{NO}_{2}$ tropospheric column from satellite $\left(C_{S}\right)$ and its error $\left(\Delta C_{S}\right)$ are estimated using DOAS technique;

ii) Similar quantities are obtained from the model $\left(C_{M}\right.$ and $\left.\Delta C_{M}\right)$ by integrating the vertical profile to get the tropospheric columns (the model vertical extension is up to $4 \mathrm{~km}$ a.g.1). All the $C_{M}$ whose central latitude and longitude match the satellite ground pixel area are then averaged to get the final $C_{M}$ and $\Delta C_{M}$ is its variance (see Fig. 1).

iii) A corrected column $\left(C_{C}\right)$ is thus calculated using $C_{M}$ and $C_{S}$ according to the following formula

$$
\mathrm{C}_{\mathrm{C}}=\left[\left(\frac{\mathrm{C}_{\mathrm{S}}^{2}}{\Delta \mathrm{C}_{\mathrm{S}}}+\frac{\mathrm{C}_{\mathrm{M}}^{2}}{\Delta \mathrm{C}_{\mathrm{M}}}\right)\right] /\left(\left(\frac{\mathrm{C}_{\mathrm{S}}}{\Delta \mathrm{C}_{\mathrm{S}}}+\frac{\mathrm{C}_{\mathrm{M}}}{\Delta \mathrm{C}_{\mathrm{M}}}\right)\right]
$$

where $C_{C}$ is a weighted average between $C_{M}$ and $C_{S}$ where the respective errors are the weights;

iv) An average $\mathrm{NO}_{2}$ profile corresponding to the satellite ground pixel is calculated from the model simulations and the respective column is scaled so to be equal to $C_{C}$ obtaining then a corrected profile. The Ground Level concentration thus Corrected is considered our final product $\left(\mathrm{GLC}_{\mathrm{NO} 2}\right)$. 
The goal of the weighted average at step (iii) is to give more importance to the more reliable columns values. As we can argue from figure 1 the SCIAMACHY ground pixel contains several TCAM cells. So we decided to choose the $C_{M}$ variances as its errors since it is a rough estimation of the possible variability of $\mathrm{NO}_{2}$ modeled column within the SCIAMACHY pixel.

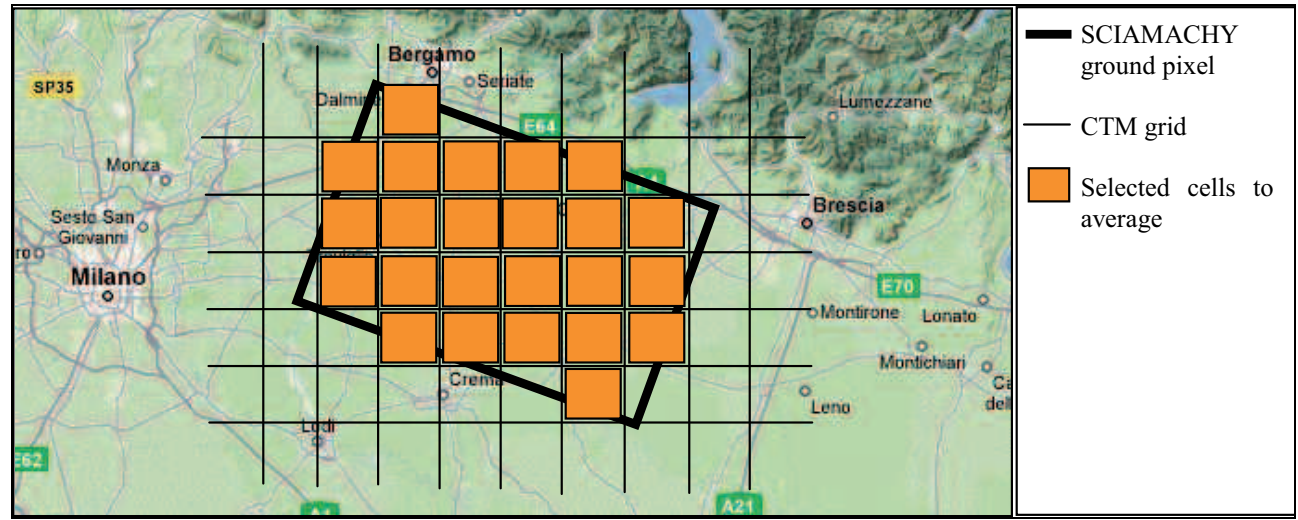

Figure 1. At each overpass all the TCAM simulations whose latitude and longitude match the satellite ground pixel area (orange squares) are considered to calculate and average $\mathrm{NO}_{2}$ column from the model $\left(\mathrm{C}_{\mathrm{M}}\right)$.

\section{CASE STUDY APPLICATION}

The method explained in the previous section has been used to get $\mathrm{GLC}_{\mathrm{NO} 2}$ concentrations during 2004 in the Po valley region that is the target area to investigate within the QUITSAT project. In figure 2 we present two case studies for November $20^{\text {th }}$ (on the left part of the figure) and January $28^{\text {th }}$ (on the right part of the figure). The first row contains the respective concentration at ground level simulated with TCAM at 10 am LT, the second one the $\mathrm{NO}_{2}$ tropospheric column as obtained by the SCIAMACHY sensor and the third one the $\mathrm{GCL}_{\mathrm{NO} 2}$ concentration (see step iv in the previous section).

Concerning the November $20^{\text {th }}$ we can see immediately a similar pattern between the first two rows meaning that probably great part of the $\mathrm{NO}_{2}$ observed and simulated is located in the lowest troposphere. This does not seem to be completely true for the January $28^{\text {th }}$ when over Piemonte, Liguria and Mar Ligure (the eastern part of Italy represented in the map) TCAM reports low $\mathrm{NO}_{2}$ at the ground level while the column from SCIAMACHY is remarkably high (this actually makes sense if $\mathrm{NO}_{2}$ was located at higher levels). In the other parts of Po valley the patterns look similar. The third row of figure 2 gives the $\mathrm{GLC}_{\mathrm{NO} 2}$ for both considered days respectively. The pattern could be different from those of TCAM and SCIAMACHY (see November $20^{\text {th }}$ ) but also similar (January $28^{\text {th }}$ ) depending on the vertical distribution of $\mathrm{NO}_{2}$ and on the relative weights of $\mathrm{C}_{\mathrm{S}}$ and $\mathrm{C}_{\mathrm{M}}$ (see above).

In order to validate the $\mathrm{GLC}_{\mathrm{NO} 2}$ concentration we have compared the obtained values with simultaneous measurements performed in situ by the regional environmental agency (ARPA) from Emilia Romagna and Lombardia regions (see Petritoli et al., 2004 for more details on ARPA measurements). Of course the comparison between an in situ sampling and the $\mathrm{GLC}_{\mathrm{NO} 2}$ values that is referred to a $30 \mathrm{kmx} 60 \mathrm{~km}$ regions could be misleading. But this is not the case if we know what we could expect from the comparison. In previous works (Petritoli et al., 2004 and Petritoli et al., 2005) we have treated similar situations concluding that satellite measurements (and derived measurements as $\mathrm{GLC}_{\mathrm{NO} 2}$ ) give different information from in situ sampling as far as their spatial resolution will remain as large. Both observations can be homogeneous (thus comparable) if the air mass sampled by satellite is well mixed otherwise space-borne measurements will represent an average of the trace constituents in the observed area that in general is different from the in situ sampling at ground stations.

In Figure 3 the comparison between GLC $_{\mathrm{NO} 2}$ and ARPA observations is shown on the left. Only ground pixel where at least 3 ARPA observations were available have been chosen and their averages are calculated to be compared with $\mathrm{GLC}_{\mathrm{NO} 2}$. The respective variances are shown as error bars in the plot. November $20^{\text {th }}$ data show good agreement (correlation coefficient $\mathrm{R}=0.85$ ) and low variance in ARPA measurements. This could be probably connected with good horizontal mixing as explained above. A different situation we have on the January $28^{\text {th }}$. Only few data are comparable (ground pixels 2 and 6 for which we notice also that the measurements weight are relevant: in fact from figure 2 it is evident how model simulations gives higher concentration in location 6 than 2 while $\mathrm{GLC}_{\mathrm{NO} 2}$ are reversed) and in particular ground pixels 3,4,7,8,9,10 show large variances and bad correlation. Again this seems to fit our previous reasoning on the horizontal mixing of the sampled air masses. Also the pattern of $\mathrm{NO}_{2}$ ground concentration from TCAM (Fig. 2, first row) reveals possible high gradients in the nearby of the areas occupied by the above pixels. 
The plot of Figure 3 (right) shows a similar comparison between ARPA and only TCAM NO2 ground concentration calculated within the respective SCIAMACHY ground pixel so to estimate the contribution of the SCIAMACHY measurements to the $\mathrm{GLC}_{\mathrm{NO} 2}$. On the November $11^{\text {th }}$ all the data benefits of the correction while on the January $28^{\text {th }}$ only few ground pixels $(1,2,6)$ seems to improve their correlation. This is consistent anyway with the previous explanation of a no efficient horizontal mixing during this day with the consequent presence of sharp gradients in $\mathrm{NO}_{2}$ concentration.
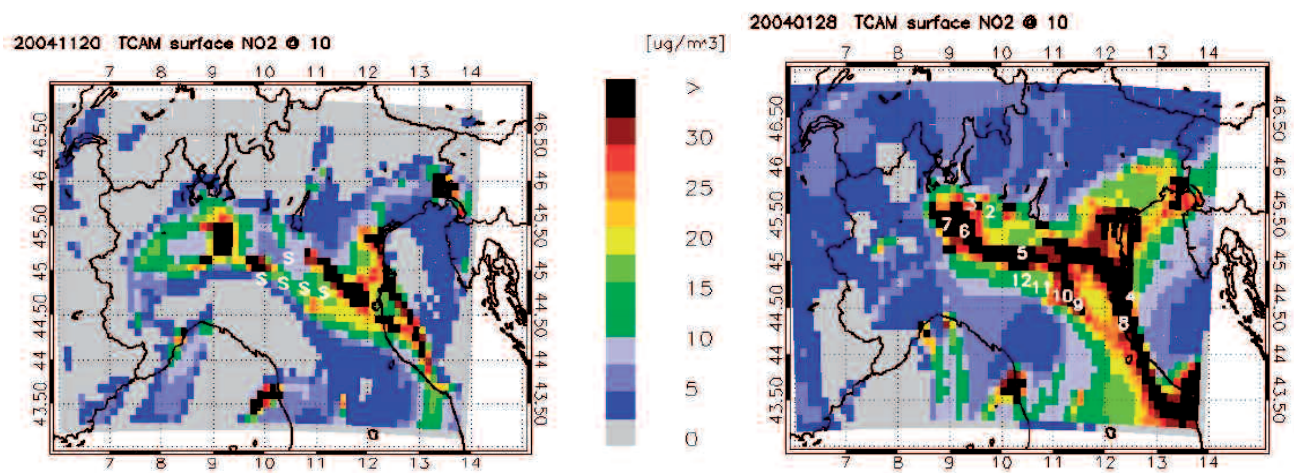

$[\mathrm{ug} / \mathrm{m}+3]$
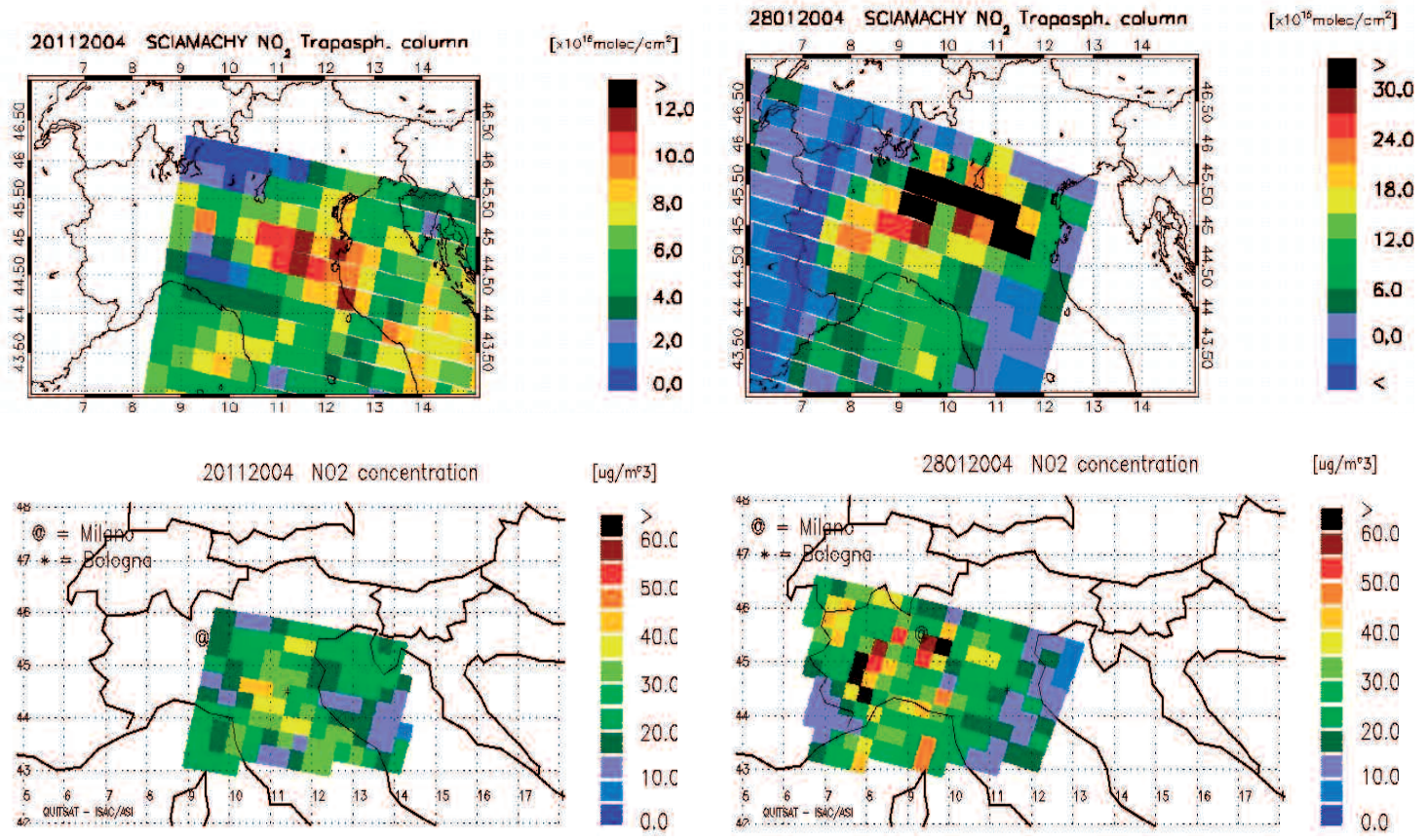

Figure 2. Two cases studies for November $20^{\text {th }}$ (on the left) and January $28^{\text {th }}$ (on the right). The first row shows TCAM NO${ }_{2}$ ground concentrations, second row SCIAMACHY $\mathrm{NO}_{2}$ tropospheric columns (note the different scales indicating higher values for January $28^{\text {th }}$ ) and the third row represents the $\mathrm{GLC}_{\mathrm{NO} 2}$ values. S labels in the picture on the left of the first row indicate the location of the SCIAMACHY pixels chosen for the comparison of Figure 3 (blue triangles) while the numbers in the same rows on the right panel associate each pixel with the respective point in the same Figure 3.

\section{CONCLUSIONS}

Satellite-borne observations of air pollution have great potentiality to be used together with CTM models to monitor air quality also at ground level. In this work we have shown a possible merging of SCIAMACHY $\mathrm{NO}_{2}$ observations with the TCAM CTM regional model. The presented method is fast (suitable then to be used for near real time monitoring) and give good results in terms of representativity of the ground level corrected $\mathrm{NO}_{2}$ concentrations $\left(\mathrm{GLC}_{\mathrm{NO} 2}\right)$ as shown by the comparison with ARPA measurements. Other space borne sensors have already improved the limitation of SCIAMACHY (like OMI with better time and spatial resolution) and even better projects are going to be developed in the near future. Considering also the high costs of maintenance of ground instrumentations this synergy is a promising road to follow for air quality science and monitoring. 

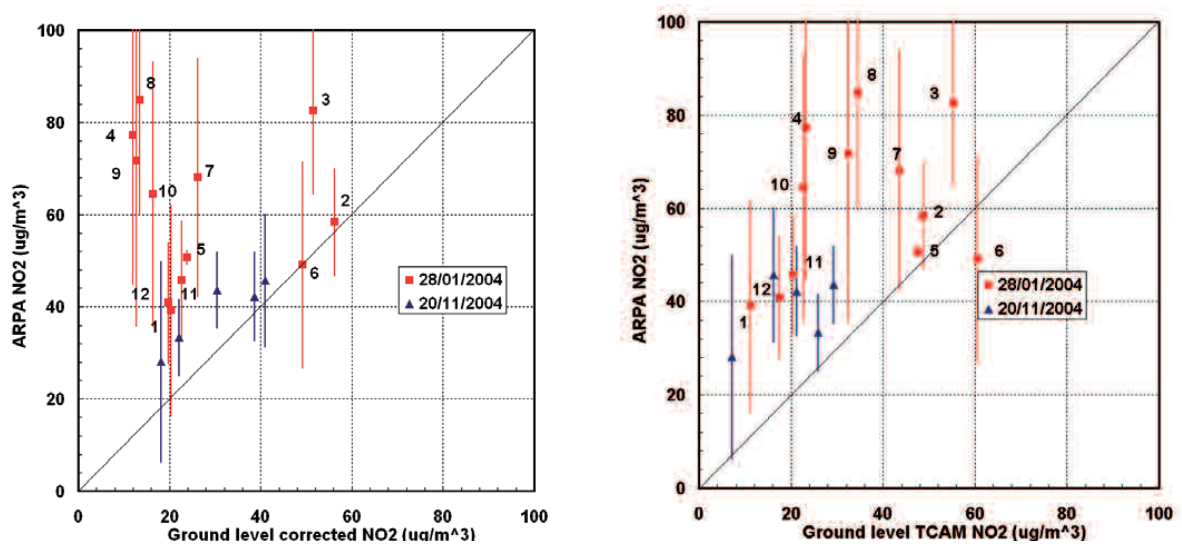

Figure 3. Comparison between ARPA ground measurements (averages of 3 measurements at least with respective variance) and $\mathrm{GLC}_{\mathrm{NO} 2}$ for November $20^{\text {th }}$ and January $28^{\text {th }}$ on the left. On the right we report the same scatter plot but with only TCAM ground level $\mathrm{NO}_{2}$ concentration (no merging with SCIAMACHY data is performed). The numbers associated with red squares series match with the location of relative SCIAMACHY ground pixel in the first row of Figure 2.

Acknowledgments: The authors would like to thank ARPA Emilia Romagna and ARPA Lombardia for providing in situ measurements and CETEMPS (Center of Integration of remote sensing techniques and numerical modelling for the forecast of severe weather of University of L'Aquila) for the initial and boundary conditions from CHIMERE simulations. The research has been developed in the framework of the Pilot Project QUITSAT (QUalità dell'aria mediante I'Integrazione di misure da Terra, da SAtellite e di modellistica chimica multifase e di Trasporto - contract I/035/06/0 - http://www.quitsat.it), sponsored and funded by the Italian Space Agency (ASI).

\section{REFERENCES}

Bovensmann, H., J.P. Burrows, M. Buchwitz, J. Frerick, S. Noël, V.V. Rozanov, K.V. Chance, A.P.H. Goede, 1999: SCIAMACHY: mission objectives and measurements modes. J. Atmos. Sci., 56, 127-150.

Burrows, J.P., M. Weber, M. Buchwitz, V. Rozanov, A. Ladstätter-Weißenmayer, A. Richter, R. Debbek, R. Hoogen, K. Bramstedt, K.-U. Eichmann, M. Eisinger, D. Perner, 1999: The global ozone monitoring experiment. (GOME): mission concept and first scientific results, 56, 151-175.

Carnevale, C., E. Decanini and M. Volta, 2008: Design and validation of a multiphase 3D model to simulate tropospheric pollution. Science of The Total Environment, 390, 166-176.

Elbern, H. and H. Schmidt, 2001: Ozone episode analysis by four-dimensional variational chemistry data assimilation. Journal of Geophysical Research, 106, D4, 3569-3590.

Lahoz, W.A., Q. Errera, R. Swinbank and D. Fonteyn, 2007: Data assimilation of stratospheric constituents: a review. Atmos. Chem. Phys., 7, 5745-5773.

Palazzi, E., A. Petritoli, G. Giovanelli, I. Kostadinov, D. Bortoli and F. Ravegnani, 2005: PROMSAR: A multiple scattering atmospheric model for the analysis of DOAS remote sensing measurements. Adv. Space. Res., 36, 1007-1014.

Petritoli, A., P. Bonasoni, G. Giovanelli, F. Ravegnani, I. Kostadinov, D. Bortoli, A. Weiss, D. Schaub, A. Richter and F. Fortezza, 2004: First comparison between ground-based and satellite-borne measurements of tropospheric nitrogen dioxide in the Po basin. J. Geophys. Res., 109, D15307, DOI: 10.1029/2004JD004547.

Petritoli, A., E. Palazzi, C. Volta, G. Giovanelli, 2006: Validation of $\mathrm{NO}_{2}$ tropospheric column from space in the Po valley Italy. TROPOSAT-AT2 annual report 2005, Ed. Borrell Burrows, 308-312.

Platt, U., 1999: Modern methods of the measurements of atmospheric trace gases. Phys. Chem., 1, 5409-5415.

Richter, A. and J.P. Burrows, 2002: Tropospheric $\mathrm{NO}_{2}$ from GOME measurements. Adv. Space Res., 29, 1673-1683.

Richter, A., J.P. Burrows, H. Nuss, C. Granier and U. Niemeier, 2005: Increase in tropospheric nitrogen dioxide over China observed from space. Nature, 437, 129-132.

van der A, R.J., H.J. Eskes, K.F. Boersma, T.P.C. van Noije, M. Van Roozendael, I. De Smedt, D.H.M.U. Peters, E.W. Meijer, 2008: Trends, seasonal variability and dominant $\mathrm{NO}_{\mathrm{x}}$ source derived from a ten year record of $\mathrm{NO}_{2}$ measured from space. J. Geophys. Res., 113, D04302, DOI:10.1029/2007JD009021.

Veefkind, J.P., J.R. de Haan, E.J. Brinksma, M. Kroon and P.F. Levelt, 2006: Total ozone from the Ozone Monitoring Instrument (OMI) using the DOAS technique. IEEE Trans. Geosci. Remote Sensing, 44, 1239-1244.

Volta, M. and G. Finzi, 2006: GAMES, a comprehensive Gas Aerosol Modelling Evaluation System. Environ. Model. Software, 21, 587-594.

Wenig, M., N. Spichtinger, A. Stohl, G. Held, S. Beirle, T. Wagner, B. Jahne and U. Platt, 2003: Intercontinental transport of nitrogen oxide pollution plumes. Atmos. Chem. Phys., 3, 387-393. 